\title{
Representaciones geopolíticas: Chile y Argentina en Campos de Hielo Sur
}

\section{Geopolitics representation: Chile and Argentina in Campos de Hielo Sur ${ }^{1}$}

Karen Isabel Manzano Iturra*

Resumen

La geopolítica, desde el concepto acuñado en 1917 por Rudolf Kjellen, ha estado en continua evolución hasta el día de hoy. Desde la incorporación de las representaciones, la primera ha sido de vital importancia en los análisis de diferentes conflictos territoriales. A través de un análisis geopolítico es que en el presente artículo se pretende comprender las representaciones geopolíticas en la zona de Campos de Hielo Sur, el último problema de límites que aún se mantiene en suspenso entre Chile y Argentina y el cómo es que ambos países han discutido el problema a partir de una serie de representaciones en las que los mapas han constituido la imagen del uno frente al otro, privilegiándose de este modo la competencia entre los Estados.

Palabras clave: geopolítica, representación, conflicto, mapas, imagen.
Abstract

From a concept first articulated by Rudolf Kjellén in 1917, geopolitics has continuously evolved up to the present. The incorporation of the initial representation has been of vital importance in the analysis of different territorial conflicts. Through a geopolitical analysis, this article aims to understand the geopolitical representations in the area of Campos de Hielo Sur, the last boundary issue that remains pending between Chile and Argentina, in addition to the manner in which both countries have debated this issue, on the basis of a number of representations in which maps have generated the image of one state facing the other, thus privileging competition between them.

Keywords: geopolitics, representation, conflict, maps, image.

Recibido: 11 de marzo de 2015.

Aprobado: 1 de octubre de 2015.

${ }^{1}$ Este trabajo pertenece a la tesis "Geopolítica Austral, el caso de Campos de Hielo Sur”, desarrollado para obtener el grado de Magíster en Ciencias Políticas, Seguridad y Defensa, en la Academia Nacional de Estudios Políticos y Estratégicos, cuyo profesor guía fue el Dr. Juan Eduardo Mendoza Pinto.

* Universidad de Concepción. Dirección: Víctor Lamas, núm. 1290, Concepción, Región del Bío-Bío, Chile. Correo electrónico: kmanzano@udec.cl 


\section{Introducción}

Desde el establecimiento de los primeros asentamientos españoles en territorio americano, los dibujos del Cono Sur fueron evolucionando, desde unas cuantas millas hasta su extensión real, dependiendo de la cantidad de viajes y exploraciones que se realizaban en cada una de las regiones, surgiendo de esta forma la visión del continente como tal, que sólo se terminó en el siglo xix con las expediciones inglesas en los canales australes. La Patagonia, durante siglos fue un lugar poco explorado por los europeos, quienes sólo se dirigieron a estas zonas mediante expediciones marítimas (Sarmiento, Ladrillero, Malaspina, Moraleda) reconociendo las costas, islas y sólo algunos, se internaron en los bosques (como los jesuitas de las misiones de Chiloé al área del lago Nahuelhuapi, actual Bariloche). Pero más al sur, el clima impedía llegar hasta la cordillera misma. Por ello, zonas más alejadas se conocieron recién a finales del siglo xIx e inicios del xx, cuando Chile y Argentina ya se encontraban en medio de las disputas por sus límites, siendo uno de aquellos puntos los denominados Campos de Hielo Sur o los Hielos Continentales.

Campos de Hielo Sur, constituye un lugar de incalculable valor estratégico desde el punto de vista geopolítico, en especial por los recursos naturales que contiene en su interior, algo que para los Estados limítrofes es esencial para el futuro. A raíz de fenómenos como el cambio climático que está afectando a escala global a diversas regiones del mundo, y cuya consecuencia más visible es la pérdida de parte de las reservas de agua en varios lugares, por la disminución de las precipitaciones y por la continua explotación antrópica, los puntos donde se encuentran posibles recursos acuíferos se transforman en partes vitales de las estrategias de los Estados. Sin duda, este sector que está siendo sometido a litigio fronterizo, constituye una de aquellas zonas en el mundo donde las potencialidades son relevantes no sólo para el desarrollo económico y energético, sino también para las necesidades de su población.

Considerando estas circunstancias, es necesario analizar y comprender las representaciones que han surgido en este determinado espacio, haciendo mención a los mapas existentes entre ambos estados desde hace décadas, con lo cual se pueden percibir los intereses de los actores involucrados y sus principales objetivos en esta zona, las que motivan la creación 
de estas cartografías que se contraponen por un determinado lugar. El presente artículo analizará una serie de mapas de Chile, Argentina y los Campos de Hielo o Hielo Continentales, que se encuentran en sitios web públicos y al alcance de las personas en general, además de fuentes escritas primarias, secundarias y terciarias, especialmente en áreas de estudio como la geopolítica, que intenten responder a las preguntas que encierra la continua creación de mapas sobre un área alejada pero que puede entregar valiosas pistas en el análisis de las proyecciones chileno-argentinas en la zona austral.

\section{Geopolítica y representación}

En el desarrollo de la geopolítica, el territorio siempre ha sido un elemento clave del análisis, tanto de la escuela clásica alemana, como de la nueva escuela francesa o crítica anglosajona. A partir de sus orígenes, este constituyó una pieza fundamental pues era el espacio donde se desarrollaba el único actor de la época: el Estado-nación, siendo los geógrafos quienes iniciaron los primeros estudios que dieron forma a una nueva disciplina, cuyo nombre es usado por Rudolph Kjellen en 1917. Las principales escuelas se desarrollaron en Europa, en torno a los trabajos de geógrafos como Frederich Ratzel o Paul Vidal de la Blanche, quienes desde el determinismo hasta el posibilismo, influenciaron a la escuela alemana y francesa de la misma. Mientras tanto, en Inglaterra y Estados Unidos, se consolidaban estas ideas por medio del heartland de Halford Mackinder o el poder naval de Alfred Mahan.

Tras el fin de la escuela alemana, Yves Lacoste (1990), representante de la nueva escuela francesa, rescata la importancia del territorio en el análisis sobre la materia, señalando que sin geografía no puede existir la geopolítica, ya que ambas se complementan, adjudicando a la primera un rol central. El autor explica que dentro de ella existen varios niveles, siendo uno de ellos "los Estados Mayores", aquellos grupos que utilizando la geografía y sus conocimientos pueden utilizarla como una herramienta de poder, en aspectos económicos, políticos y militares. Esta idea, según Yves Lacoste, es clave dentro de la geografía, en vez de la cortina de humo que se mantiene en la educación, donde se repiten las características de una 
región o la llamada geopolítica de los profesores. A juicio de este autor, en su texto clásico La geografía, un arma para la guerra:

Plantear de entrada que la geografía sirve, en primer lugar, para hacer la guerra no supone que sólo sirva para dirigir unas operaciones militares; sirve también para organizar los territorios no sólo en previsión de las batallas que habrá de librar contra tal o cual adversario, sino también para controlar mejor a los hombres sobre los cuales ejerce su autoridad el aparato del Estado (Lacoste, 1990, p. 7).

Desde los primeros imperios de la antigüedad, el geógrafo siempre sirvió a intereses superiores de su estado o ciudad, ${ }^{2}$ brindando información valiosa de sus viajes por ciertos territorios, los cuales observaba con atención, para entregar sus conocimientos a través de sus relatos y de los mapas, los cuales podían señalar las rutas de futuras campañas e invasiones militares, que se dirigían por terreno seguro sabiendo las características de la geografía, los pueblos y las riquezas que existían, algo que se puede observar dentro de las primeras obras clásicas, como los Nueve Libros de la Historia de Heródoto de Halicarnaso, donde las primeras secciones se encargaron de mostrar a los griegos el mundo antiguo, sus costumbres y riquezas.

Bajo esta lógica, los países comprendieron la importancia de proyectarse de acuerdo a los mapas que estaban elaborando, ya que estos constituían una "herramienta de información científica y de manipulación política, un material para el análisis geopolítico critico" (Goudin, 2010, p. 142) en el cual se lograba observar tanto su mentalidad (frente al mundo) o sus áreas valiosas (proyecciones), reclamando ciertos territorios perdidos en una guerra o a los cuales les interesa dominar, ${ }^{3}$ para mantener la

${ }^{2}$ En la Antigua Grecia, donde el geógrafo era la primera fuente de conocimiento sobre lugares lejanos. Basta recordar las obras de Heródoto, los Nueve Libros de la Historia, donde los cinco primeros contienen importantes datos de otras culturas, como Egipto.

${ }^{3}$ La mentalidad de los pueblos se puede observar en su ubicación geográfica del mundo, como por ejemplo, los países de Occidente que han mantenido el planisferio donde Europa era el centro, pero existen mapas medievales donde Jerusalén estaba en la ubicación privilegiada, por su concepción cristiana. En cuanto a los mapas que reclaman territorios perdidos, existen casos cercanos como Bolivia, donde el mapa del 
eficacia de su discurso frente a otros, especialmente en sus vecinos cercanos o en la región donde se encuentra, ya sea por medio del expansionismo o para defenderse de los intereses de otro. El mapa esta creado, bajo esta idea de la representación francesa, para ciertos fines, ya que es una prueba a la que se debe mirar con ojo crítico, pues no fue fabricada de manera inocente por quienes las encargaron, sino que trabaja en función de los Estados Nación que los desarrollaban para mostrar sus intenciones, acciones y principales objetivos, donde se consigue valiosa información de sus intereses, pero también entregando argumentos para el análisis geopolítico, los cuales podrían utilizarse tanto en tiempo de paz como de conflicto, en que se puede desestabilizar a un determinado actor mediante este sistema y generar una imagen de victimización frente a los demás.

Sin duda, el territorio genera ciertas condiciones para los países involucrados, ya que "un territorio es un espacio apropiado y ocupado por un grupo, que lo entiende como parte de su identidad" (Goudin, 2010, p. 291), por lo tanto, será para ellos un elemento de unidad, orgullo, desazón o tristeza, desde los mapas imperiales con la máxima extensión, o constituyendo un sentimiento de luto o tristeza donde se lamentará ese pasado glorioso, que por diferentes guerras o firmas de tratados bilaterales, terminó mermando la acción del Estado sobre su espacio original.

Dentro de ello, destaca este concepto de las representaciones, en que Yves Lacoste, determinó que en todos los dilemas geopolíticos se encontraban involucrados bajo estos términos, los cuales influyen en cómo se ven los actores unos a otros. Dentro de las representaciones se encuentran presentes los siguientes elementos:

a) Actores: son capaces de movilizar recursos en el sistema internacional, entes activos en un territorio y de los cuales su interacción con otros produce tanto cooperación como confrontación.

b) Poder: la geopolítica es política en torno al espacio dentro del cual se mueve el poder, para ganar la voluntad del otro. Las relaciones de poder pueden dirigirse entre el resguardo, conquista o refuerzo.

c) Espacio: es donde se movilizan los actores y el lugar físico donde se desarrolla el poder, lo componen la naturaleza y la sociedad. El

luto ha sido utilizado por innumerables gobiernos que han culpado a la falta de mar sus problemas de desarrollo. 
conflicto es un elemento esencial de la geopolítica que no existe sin un espacio.

La noción de representación, que surge de esta triada de elementos, va mas allá del plano real donde se sitúan los acontecimientos, pues incorpora las imágenes y la percepción sobre los demás, mediante la creación de mapas que establecen las formas en que cada país se ve a sí mismo y su alrededor. Se entiende por percepción el "proceso integrativo por el cual los estímulos llegan a ser interpretados por el individuo, produciéndose dicho proceso como resultado de la integración de los hechos que suponen un estímulo con los conocimientos previos y creencias del actor" (Herrero, 2006, p. 143), por lo cual, basándose en estos mapas, unidos a la serie de juicios que rodean las acciones de los Estados, se logran establecer ciertos parámetros que se transforman en percepciones, generándose la visión de vencedor y víctima, los cuales pueden ser enseñados a la población por medio de imágenes, en donde las cartografías adquieren vital relevancia. Surgen entonces los imaginarios, que se pueden comprender como:

Conjunto de imágenes mentales que confieren, a un individuo o un grupo, un significado y una coherencia en cuanto a su localización, distribución, interacción de los fenómenos en el espacio. El imaginario contribuye a organizar las concepciones, las percepciones y las prácticas espaciales (Debarbieux citado en Claval, 2012, p. 32).

Ambos conceptos son fundamentales para comprender las visiones que surgen en los países frente a los demás, pues generan imágenes en torno a un determinado territorio. Paul Claval, uno de los máximos exponentes de la escuela francesa, estima que "el imaginario vuelve a estructurar las representaciones que los individuos elaboran del mundo exterior y las imágenes nutridas de sueños y fantasmas" (Claval, 2012, p. 30). Por lo tanto, desde el punto de vista de los Estados, se debe entregar una visión para que las personas se identifiquen con un lugar o territorio determinado. Ciertamente en otros lugares, la influencia de la sociedad afecta a las visiones de las zonas, pero cuando estas se encuentran más alejadas, se debe crear un lazo que los una de manera estable, 
generándose dos imaginarios, uno centralizado, dependiente de las autoridades máximas de los países en cuestión y regionales, donde los habitantes que se encuentren más próximos defienden su propia conexión con ese lugar, pues a juicio de Vincent Berdoulay "la búsqueda creciente de afiliaciones y de signos de identidad de ciertas poblaciones, genera un espejo amplificador" (Berdolay, 2012, p. 60). Las representaciones serán el reflejo de estas imágenes en documentos oficiales, como mapas, pero también extraoficiales, donde es posible observar cómo ha traspasado a los diferentes grupos de la sociedad las cartografías que se generan en torno a diferentes problemas fronterizos, formulándose un sentimiento de asociación con la zona cuestionada y la defensa de los territorios frente a otros estados, pues, como lo comprende Nogué "la generación de imaginarios sociales o colectivos provenientes de procesos de comunicación intrapersonal representa el primer nivel de interacción comunicacional posible" (Nogué, 2012, p. 130), con ello se puede entender que:

Las acciones asociadas a la definición de territorialidad de la nación estaban —y están- cargadas de subjetividad, de intención, de propósitos, todas proyectadas desde una estructura social, normalmente vinculada a valores forjados desde el ámbito de poder. Estos valores no son, entonces, tabula rasa, sin extensión, sin un carácter, sin un cuerpo social de poder que los respalde (Laurín y Nuñez, 2013, p. 86).

Por lo tanto, estas representaciones, que reúnen en sí mismas tanto imágenes como imaginarios propios de las zonas que se encuentran en disputa, se enmarcan dentro de una determinada concepción de espacio, la cual se asocia a un determinado estado o país, o a un grupo de habitantes que se siente identificado con un lugar, un tema que ha sido analizado también en la escuela de geopolítica crítica, donde sus autores plantean el rol del discurso. John Agnew se refiere al tema del espacio, definiendo esta situación como la "trampa territorial", la cual puede ser comprendida como "la proyección histórica de un mundo en que el poder sobre los otros se concibe como algo que está repartido entre entidades de soberanía territorial semejantes" (Agnew, 2005, p. 57), es decir, un espacio que está dividido entre diferentes países, y que conlleva, en consecuencia, a desarrollar problemas limítrofes cuando sus intereses chocan con sus vecinos, a 
los cuales les interesa instalar y desarrollar su poder en el mismo contexto geográfico. Por ello, tanto las ideas de la geopolítica francesa, el juego de los mapas y los imaginarios se asocian a la trampa territorial planteada por la geopolítica critica, ya que intentan responder las mismas dudas, por que a los estados les interesa proyectar su poder en un determinado lugar, arriesgándose a disputas con otros, las cuales pueden ser resueltas a través de conversaciones o enfrentamientos, pero que responden sólo a lo que guardan en su interior, constituyendo la base de las representaciones geopolíticas.

El juego del mapa y las trampas no tendrían sentido si no existiera alguna idea preconcebida del poder que se interesa mostrar, para ello, las representaciones son vitales y las cartografías una herramienta útil a desarrollar. Sin duda, a pesar de que la geopolítica crítica se concentra más en el discurso que en la geografía, sus aportes son muy útiles ya que complementan las ideas de las representaciones con las proyecciones en un determinado lugar, pues no tendrían una razón significativa si no buscaran algo en el territorio, ya sean los recursos naturales que los estados intentan extraer, o puntos donde movilizar sus discursos.

Bajo este análisis, América Latina no ha escapado de esta situación, especialmente cuando los nuevos Estados acceden a su independencia, exigiendo la herencia colonial del Uti Possidetis, o los antiguos límites hispanos para sus respectivos países, lo que en vez de favorecer los entendimientos perjudicó las conversaciones. Se decidió este principio rector para las naciones, en momentos en que todavía extensas áreas no habían sido ocupadas por los gobiernos centrales, y la realidad demostraba que los centros urbanos se encontraban separados unos de otros por kilómetros de distancia, pues las autoridades coloniales no hicieron efectivo el dominio completo de cada virreinato, gobernación, capitanía general y audiencia. En esa época aún no se comprendía el valor de aplicación de este principio, ya que posteriormente se entendió que traería consecuencias en las relaciones diplomáticas, por conseguir estos kilómetros dentro de su jurisdicción, reclamando estos espacios vacíos para extender su poder, utilizando los mismos elementos jurídicos de dicho Uti Possidetis.

Además de este problema, con el paso de los años se descubrió que existían dualidad de cartografías e imágenes, abriendo una serie de 
interrogantes para los gobiernos y con ello, el inicio de un periodo de conflictos que han incluido guerras entre varios Estados, ${ }^{4}$ ofensivas diplomáticas en tribunales internacionales y reclamaciones territoriales en la actualidad, ya que "la documentación cartográfica imprecisa de la época respondía además a cierto desinterés del reino español por el dominio sobre el territorio y a una mayor preocupación por el dominio sobre los súbditos, como vestigios de las concepciones de poder heredadas del feudalismo" (Lucero, 2007, p. 18), es decir, como cada uno de los territorios se encontraban bajo la misma autoridad, no era necesario fijar criterios claros de delimitación, problemas que heredaron los nuevos Estados cuando buscaron establecer sus límites. Chile y Argentina se han movilizado en este mismo contexto de imágenes a lo largo de su relación bilateral, por medio de la recuperación de los antiguos datos coloniales para afirmar su posición frente al otro, y con ello, permitir una serie de expectativas tanto dentro como fuera de sus fronteras.

\section{Cartografías opuestas chileno-argentinas}

Desde el siglo xix, en especial cuando se comienza a trabajar las primeras teorías de reclamación chileno-argentina de la zona patagónica, se desarrollaban con fuerza una serie de ideas, motivadas por la instalación de Fuerte Bulnes en el Estrecho de Magallanes, momento en el cual Argentina reclamó formalmente a Chile este acto pues consideró que dicha fundación se había asentado en una zona de su propiedad. Fue entonces que se comenzaron a utilizar diferentes cartografías coloniales que contraponían los puntos de vista de ambos países, pretendiendo bajo las mismas herramientas las zonas de Magallanes y los pasos australes.

${ }^{4}$ El periodo más conflictivo fue el siglo xix, cuando las disputas fueron solucionadas a través de guerras a gran escala, como la Guerra de la Triple Alianza, donde Argentina, Brasil y Uruguay se enfrentaron a Paraguay (1864-1870) y la Guerra del Pacífico, que enfrentó a Perú y Bolivia contra Chile. La cantidad de estados involucrados en ambos casos y las transformaciones territoriales al mapa de Sudamérica son un ejemplo de cómo las disputas se solucionaron por esta vía. Pero ello no ha significado que el siglo xx haya sido tranquilo, pues hasta la década del noventa se desarrollaron guerras, como la Cordillera del Cénepa, entre Ecuador y Perú. 
Chile comenzó a usar como base fundamental de sus demandas el mapa de Cano y Olmedilla (1775) donde se graficaba a la Capitanía General con una jurisdicción que se extendía al otro lado de los Andes desde el río Diamante al sur, incluyendo una amplia zona correspondiente a la Patagonia, con lo que se aseguraba el absoluto dominio del Cono Sur americano y la bioceanidad (Pacífico-Atlántico) que fueron replicadas en posteriores cartografías. Este mapa, contaba con detractores, ya que no había actualizado las divisiones administrativas del periodo de los Borbones, que un año después, establecía la creación del Virreinato del Río de la Plata a partir de las gobernaciones de Paraguay, Río de la Plata, audiencia de Charcas y la extracción de la provincia de Cuyo, San Juan y San Luis, que hasta ese momento pertenecían a Chile, pasándolas a manos de la nueva administración. A pesar de ello, se siguió desarrollando la idea del río Diamante como línea demarcatoria del territorio chileno al sur.

Mientras tanto, en Argentina se manejaban otro tipo de mapas y documentos. Uno de los más relevantes y utilizados, el de D’Anville (1748) otorgaba a la gobernación de Buenos Aires la propiedad de las costas patagónicas, y la zona continental dividida por una línea "con un tercio para el Río de la Plata y dos tercios para el Reino de Chile" (Lacoste, 2004, p. 225), cuya representación cartográfica marcó el desarrollo de mapas dentro de Argentina durante el siglo XIx, ya que le entregaba una imagen de pertenencia en las regiones australes. Además de las representaciones, uno de los documentos más importantes data del periodo anterior a la fundación de Buenos Aires, la Real Cédula de 1570 que definía los límites de la jurisdicción de la época. Esta había sido otorgada a Juan Ortíz de Zárate por el rey Felipe II, cuyo fin era "desplazar la frontera austral de la Gobernación del Río de la Plata, del meridiano 3657' al 48 21' 15” de latitud sur" (Lacoste, 2002, p. 217) siendo posterior a las lonjas entregadas a Simón de Alcazaba y Pedro de Camargo, ${ }^{5}$ los cuales no pudieron realizar el dominio efectivo de las zonas en cuestión, solo reconocimientos parciales en momentos que ni la propia cartografía sudamericana estaba completa. Pero esta Cédula tampoco generó cambios significativos, ya que la conquista

${ }^{5}$ Simón de Alcazaba y Francisco de Camargo obtuvieron del rey Carlos V las capitulaciones de dominio de una parte de Sudamérica. En el caso de Simón de Alcazaba se le entregó la Gobernación de Nuevo León, y luego esta fue cedida a Francisco de Camargo y extendida hasta el Estrecho de Magallanes. 
se concentró en las zonas del interior y en la costa se determinó la fundación de Buenos Aires de manera tardía (1580). ${ }^{6}$

En el periodo de la conquista, la Gobernación del Río de la Plata tenía jurisdicción sobre los territorios de la zona oriental de Sudamérica, pero en la Patagonia se le consideraba "como territorios desolados, carentes de riqueza y poco adecuados para el asentamiento de los europeos" (Lacoste, 2002, p. 224) por lo tanto, no existió una preocupación real por la zona, permaneciendo alejado del foco de atención. Pero dichos títulos sí fueron utilizados dentro de los estudios de Pedro de Angelis y Dalmacio Vélez Sarsfield, quienes comenzaban a reclamar los derechos de Argentina en la zona patagónica y austral, desde la década de 1850. Esto generaba el inicio de las demandas formales sobre la zona meridional del cono sur, y con ello, de recuperar los títulos anteriores al proceso de emancipación, para fundamentar dichas teorías. Pero no sólo ocurría en Argentina. En Chile durante el mismo periodo, Miguel Luis Amunátegui y Carlos Morla Vicuña, investigaban el dominio en la Patagonia, siendo el segundo quien encontró indicios de la Real Cédula de 1570 , pero que no logró convencerlo, pues se encontraron datos en la recopilación de Leyes de Indias de 1680. Amunátegui explicaba que:

Todo el dicho reino de Chile, con las ciudades, villas, lugares y tierras que se incluyen en el gobierno de aquellas provincias, así lo que ahora está pacífico y poblado, como lo que se redujere, poblare y pacificare dentro y fuera del estrecho de Magallanes y la tierra adentro hasta la provincia de Cuyo inclusive (Amunátegui 1880, pp. 34-35).

Estos límites dejaban en 1810 la Patagonia bajo jurisdicción chilena y no argentina, pues el rey había excluido de su mención sólo a Tucumán, entregada a la Audiencia de Charcas en 1563, por lo tanto, entendió que dicho documento ya no era válido en el periodo independiente. Estas diferencias de opinión se siguieron desarrollando desde ahí en adelante reflejadas en la producción de mapas, los cuales se contraponían sobre el

${ }^{6}$ La fundación de Buenos Aires, en 1580, constituye el segundo intento hispano en el área, tras el fracaso del primer establecimiento costero en 1536, realizado por Pedro de Mendoza. La mayor parte de los esfuerzos se desarrollaban en torno a la ciudad de Asunción, que se transformó en el principal polo de esta zona de Sudamérica. 
mismo punto, la Patagonia, y con ello, la posesión futura sobre Campos de Hielo Sur. En ese sentido, se puede entender que:

En aquel momento la vaguedad en los planos era el resultado de una época en donde las enormes extensiones de tierras inexploradas permitían la existencia de mapas inexactos, sin que ello fuera la causa central de los enfrentamientos en el hemisferio. En otras palabras, la cartografía de la época era del tipo expeditivo debido, en primera medida, al desconocimiento del territorio por la precariedad en el transporte y, en segundo lugar, por la ausencia de tecnologías adecuadas para la precisión en la construcción de la topografía (Lucero, 2007, p. 18).

Estas zonas de anecúmene del cono sur, habían pasado durante siglos sin preocupación de los Estados que las reclamaban, ya que sólo las costas despertaron el interés de Chile, mientras que para Argentina la ocupación mediante campañas contra los indígenas se realizó en esta región. Se puede considerar desde ese periodo, que se inició la rivalidad geopolítica de ambos países, pues se fueron replicando en numerosas ocasiones las imágenes donde un determinado espacio, la Patagonia, pertenecía a uno solo de los involucrados, provocando una serie de prejuicios dentro de la población que favorecían las visiones de competencia entre los Estados, en vez de las posibilidades de integración mutua. En este sentido, adquiere relevancia la transposición de territorios, ya que al existir mapas disímiles, permitía sembrar la duda dentro de las personas y otros países del mundo que no conocen al fondo el problema, pero que se dejarían guiar por la mayor cantidad de pruebas o mapas existentes sobre un territorio en particular, y que pueden terminar apoyando o reprobando las acciones de un Estado sobre otro, adquiriendo una fuerte composición política y diplomática (ver figuras la y 1b). Esto se debe a que:

En este sentido, la producción cartográfica, y su objetivación en mapas definidos, interviene activamente en la configuración relacional del espacio y, gracias a un mecanismo de causalidad recurrente — esto es, la apropiación y utilización regular de determinados mapas producidos-, reproduce una imagen de mundo determinada, borra las huellas de su génesis y condiciona los modos (Aguer, 2014, p. 131). 
Figura 1a. Capitanía General de Chile-Virreinato del Río de la Plata

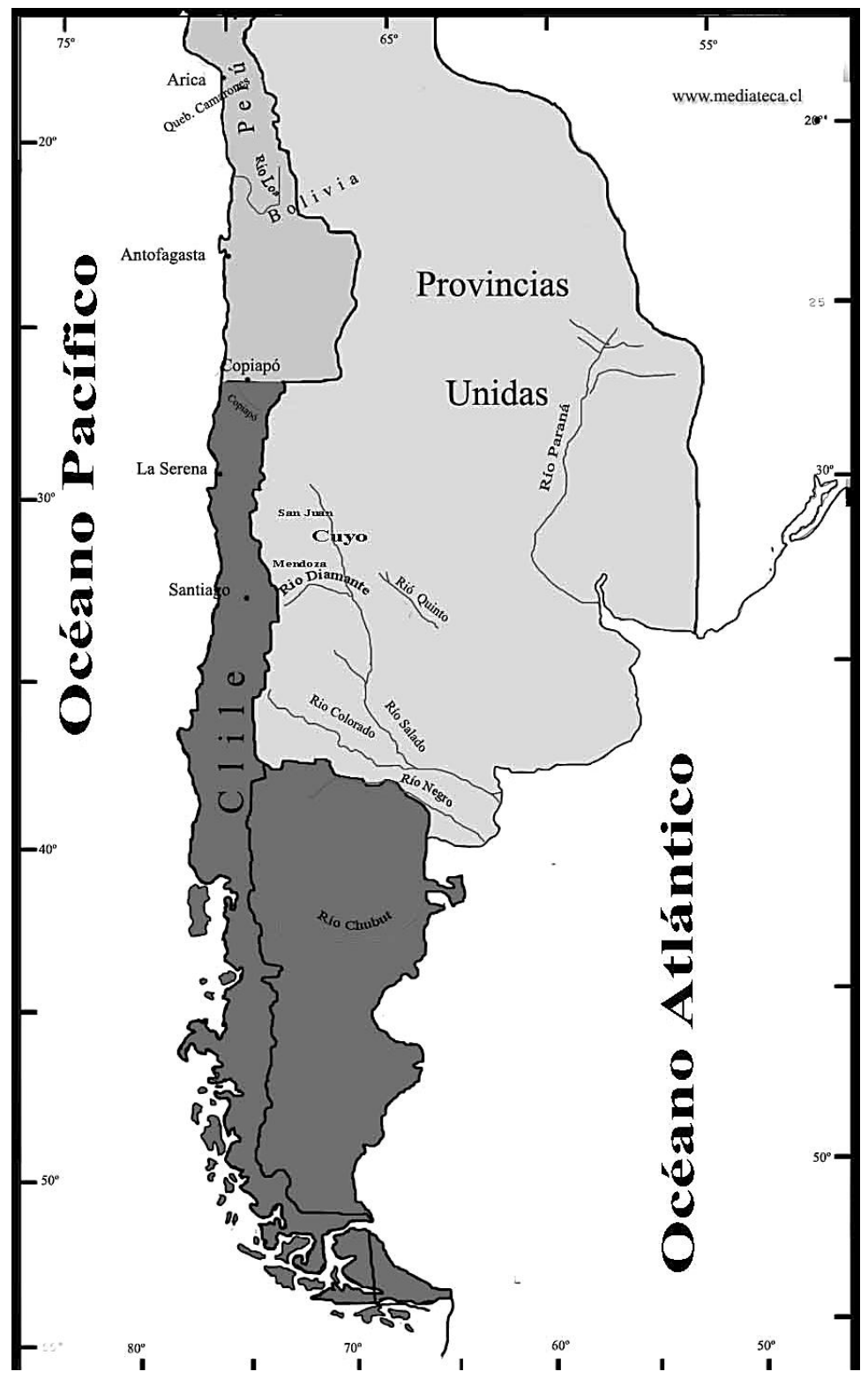

Fuente: Zamora (s.f.). 
Figura 1b. Virreinato Río de la Plata

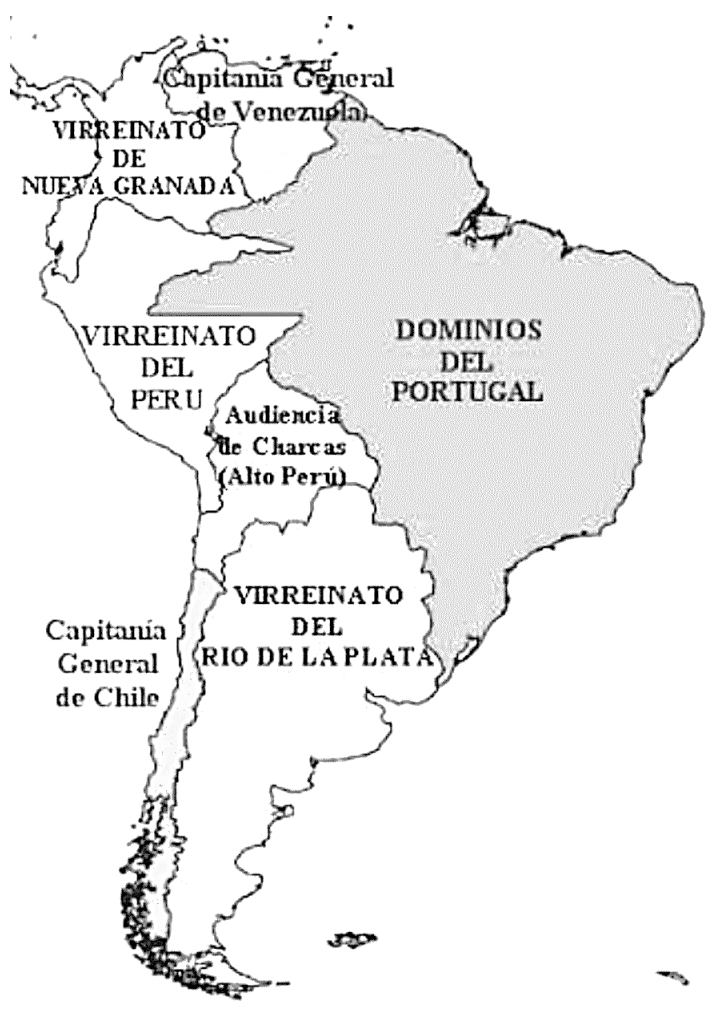

Fuente: Instituto de los Andes (s.f.).

Las figuras anteriores, son mapas que se encuentran en sitios web públicos donde demuestran las visiones antes expuestas, las cuales fueron claves en la relación chileno-argentina, ya que muestran las áreas donde cada uno de los estados tiene una proyección en particular y cómo se ha traspasado este imaginario a la población en general, que no cuenta con los medios para observar los mapas oficiales pero sí todos aquellos que se encuentran en páginas de fácil acceso. En ambos, se puede observar la idea de esplendor en algún momento dado de su historia, con una enorme extensión de territorio bajo su control, y que actualmente se encuentra 
reducido, en gran parte, por las acciones del otro, creándose la representación del vecino expansionista que impidió el mantenimiento de esa unidad y como consecuencia, la disminución de sus espacios naturales. La Patagonia, los pasos interoceánicos y los glaciares australes cordilleranos se han encontrado en varias ocasiones, en esta misma situación, en mapas donde se contraponen la jurisdicción chilena y argentina, los cuales son dados a conocer a sus habitantes, reafirmando el proceso del imaginario que rodea a las representaciones geopolíticas.

\section{Campos de Hielo Sur o Hielos Continentales}

La Patagonia, desde mediados del siglo xix se encontraba en disputa. Las negociaciones se dilataron, en especial tras una serie de autores que surgieron a ambos lados de la Cordillera que defendían a ultranza a cada Estado y que con sus escritos, favorecían a sus respectivos gobiernos. El primer tratado que se enfocaba en las cuestiones fronterizas se remonta al año 1856, cuando Chile firmó con la Confederación Argentina ${ }^{7}$ un convenio que establecía que:

Artículo 39․ Ambas partes contratantes reconocen como límites de sus respectivos territorios, los que poseían como tales al tiempo de separarse de la dominación española el año de 1810, y convienen en aplazar las cuestiones que han podido o pueden suscitarse sobre esta materia para discutirlas después pacífica y amigablemente, sin recurrir jamás a medidas violentas, y en caso de no arribar a un completo arreglo, someter la decisión al arbitraje de una nación amiga (Tratado de paz, amistad, comercio y navegación, 1856).

Como se puede observar, nuevamente se hace mención al principio del Uti Possidetis, aplazando los problemas limítrofes, en especial tras las publicaciones que comenzaban a surgir en torno a los derechos sobre la Patagonia, que en ambos lados de la Cordillera, exaltaban la tesis máxima

${ }^{7}$ Hasta 1861, se produce la separación de la Confederación Argentina y el gobierno de Buenos Aires, punto máximo de las discusiones y guerras civiles que enfrentó el país en el siglo xIx. Las marcadas diferencias entre las provincias y la capital generaron dos gobiernos, tras la caída de Juan Manuel de Rosas, en 1852. 
de dominio: o pertenecía a Chile o Argentina. Tanto Amunátegui, Morla Vicuña, Vélez Sarfield o Quezada defendían sus principios a favor de su país, encontrando tanto admiradores como detractores de sus políticas, pero cuyos mapas comenzaban a ser ampliamente reconocidos en los círculos académicos, dentro de los cuales, el mando en el cono sur era el punto geopolítico más importante a conseguir, ya que su soberanía entregaba el acceso a la bioceanidad y los pasos marítimos, en momentos en que el tráfico de embarcaciones se realizaba por el sur. La representación que surge en este periodo siguió influyendo en los posteriores gobiernos porque:

La definición de la territorialidad de la nación y con ella, de la frontera fue un proceso de configuración del espacio que no solo fue un asunto físico o geográfico, es decir, el hecho de anexar tierras así como la definición del límite fue un escenario con un trasfondo social relevante, en tanto determinadas relaciones sociales (agentes sociales) implicaron a su vez relaciones espaciales (Laurín y Núñez, 2013, p. 86).

La actitud que desarrollaban ambos gobiernos poco a poco condicionó la relación bilateral, y las tensiones motivaban una intervención en este caso para evitar un conflicto, como se temía desde los incidentes de la Jeanne Amelie y Devonshire, ${ }^{8}$ los cuales generaban incertidumbre en torno a un posible conflicto bélico, especialmente en 1878. Esto motivó que a fines de ese año, ambos Estados se comprometieran a encontrar una solución al tema limítrofe en el Pacto Fierro Sarratea, donde "la República de Chile ejercerá jurisdicción en el mar y las costas del Estrecho de Magallanes, canales e islas adyacentes, y la República Argentina en el mar y las costas del Atlántico e islas adyacentes" (Barros, 1970, p. 353), estableciendo las bases del posterior tratado de 1881. Este documento, firmado en medio de las acciones de la Guerra del Pacífico, definía claramente que:

${ }^{8}$ Ambos casos corresponden a incidentes en las costas australes, donde la Jeanne Amelie en 1876 (Francia) y el Devonshire en 1878 (Estados Unidos), que cargaban guano al sur del río Santa Cruz, fueron detenidos por las autoridades chilenas ya que no contaban con su permiso. Esto gatilló mayores problemas con Argentina, que consideraba esa zona bajo su jurisdicción. 
Artículo Primero: El límite entre Chile y la República Argentina es de Norte a Sur, hasta el paralelo cincuenta y dos de latitud, la Cordillera de los Andes. La línea fronteriza correrá en esa extensión por las cumbres más elevadas de dichas cordilleras que dividan las aguas y pasara por entre las vertientes que se desprendan a su lado y otro. Las dificultades que pudieran suscitarse por la existencia de ciertos valles formados por la bifurcación de la Cordillera y en que no sea clara la línea divisoria de las aguas, serán resueltas amistosamente por dos peritos nombrados uno de cada parte. En caso de no arribar estos a un acuerdo será llamado a decidirlas un tercer perito designado por ambos Gobiernos (Dirección Nacional de Fronteras y Límites del Estado [Difrol], 1881, párr. 5).

Este artículo contenía algunos problemas. La cordillera de los Andes, presentaba una gran formación en la mayor parte del límite, en el cual la línea de las altas cumbres y la divisoria de las aguas coincidían completamente. Pero hacia el sur, ambos principios geográficos se disociaban por completo, surgiendo las dudas sobre la base vital de la separación y demarcación, donde Chile reconocía el divortia aquarum (divisoria de las aguas en vertientes atlánticas y pacíficas) y Argentina el divortia aquarum continental (divisoria de las aguas por las altas cumbres), ya que ello podía asegurarles mayor cantidad de kilómetros. En el caso de las altas cumbres, la región de Aysén y Magallanes, posee como formación geológica clave la Cordillera Patagónica Austral, integrante de la cadena de los Andes, la cual fue reconocida en la sección norte por el explorador italiano Alberto de Agostini "por el extraordinario desarrollo de sus campos de hielo, que cubren como un inmenso manto sus áreas más elevadas" (Agostini, 1945, p. 7) en que destacan importantes alturas como el cerro San Lorenzo $(4.050 \mathrm{~m}) \mathrm{o}$ San Valentín (3.700 m). Más al sur, las elevaciones orográficas más relevantes la constituyen el Monte Fitz Roy y Daudet, donde se encuentran una gran cantidad de glaciares, como los Campos de Hielo de gran extensión, los cuales descienden hacia ambas laderas de la cordillera austral, y que en Argentina son llamados Hielos Continentales. Esta definición ha sido cuestionada, ya que se considera que por su extensión, sólo se podrían calificar aquellos que se ubican en Groenlandia o la Antártica, pero que “esta región no presenta las características geográficas propiamente dichas de un hielo continental, por lo tanto la calificación de Campos de Hielo 
Continentales Sur escogida por Chile, resulta la más adecuada" (Lucero, 2007, p. 51).

Geográficamente, los campos de hielo se ubican entre "los $48^{\circ} 15$ y $\operatorname{los} 51^{\circ} 35^{\prime}$ de latitud Sur y las longitudes $73^{\circ} 00^{\prime}$ y $74^{\circ} 00^{\prime}$ Oeste. Tiene una superficie de 13.900 kilómetros ${ }^{2}$, de los cuales más de tres cuartos pertenecen a Chile; una parte menor de Campo de Hielo Sur es limítrofe con Argentina" (Congreso Nacional, 2009, p. 8), por lo cual su existencia es relevante en el sistema de aguas austral. Según un estudio de Börgel, este "alimenta varias lenguas de glaciar que se derraman hacia el Pacífico, cayendo en cliff o acantilados, como también hacia el Este, sobre los lagos argentinos" (Börgel, 1995, p. 10), incluso el mismo autor confirmaba que dentro de los casquetes de hielo este "es el tercero en tamaño, después de la Antártica y Groenlandia” (Börgel, 1995, p. 10), lo que transforma a este lugar en una importante reserva de agua en estado sólido a nivel mundial. Se considera un remanente de una gran masa de hielo existente hace 100.000 años en el cono sur, cuyo espesor, cercano a mil metros, se volvió un obstáculo para determinar cualquier división ya que aunque en la base del glaciar exista un relieve, el hielo lo remontará si es que este no se refleja también en la superficie del glaciar. La mayor parte de las cuencas corren hacia el Océano Pacífico, y solo dos, los lagos Viedma y Argentino, se encuentran en la sección del Atlántico. El mayor problema surge en los encadenamientos montañosos pues "posee dos alineamientos de altas cumbres, uno en el borde cercano al Océano Pacífico y el otro en el borde oriental sobre los lagos y mesetas de la pampa argentina” (Börgel, 1995, p. 12), por lo que el dilema ha sido siempre definir cuál de los sectores es el más importante para demarcar la frontera chileno-argentina, lo que se ha reflejado en sus respectivas cartografías.

\section{Las representaciones}

Con la definición de los aspectos geográficos claves de la zona, se puede observar que desde el inicio de las relaciones diplomáticas, tanto Chile como Argentina han trabajado en función de cartografías superpuestas, que han sido aprovechadas por los grupos más nacionalistas para continuar las 
reclamaciones territoriales. ${ }^{9}$ Tras la firma del Tratado de 1881, con el establecimiento del límite definitivo, no cesó la creación de estos mapas con el mismo problema, motivando una serie de nuevos acuerdos aclaratorios, como en 1893 para el principio bioceánico, y las negociaciones para solucionar los problemas de la divisoria en el área austral.

Campos de Hielo Sur comenzó a aparecer en los mapas luego de los trabajos de demarcación de la frontera, que abrió nuevas interrogantes, para lo que se hizo necesario recurrir a una potencia extranjera que ejerció como árbitro para estos casos. Los peritajes de Moreno y Barros Arana dieron origen en 1898 a un acta que establecía que:

Art. $1^{\circ}$ - Que, resultando de la comparación de la línea general de frontera presentada por el Perito Argentino y que consta del acta del 3 de septiembre último y de la presentada por el Perito de Chile inserta en el acta de 29 de agosto que los puntos y trechos de la primera señalados con los números (...) 304 y 305 , concuerdan con los puntos y trechos de la segunda señalados con los números (...) 331 y 332, resuelven aceptarlos como formando parte de la línea divisoria en la cordillera de los Andes, entre la República Argentina y la República de Chile (Lucero, 2007, p. 22).

El acta, estableció que el límite en la zona correspondiente a los Campos de Hielo, se dibujó como una línea recta que dividía los glaciares entre los Estados, ya que como se explicaba anteriormente, los puntos entre los peritos concordaron, comprendiéndose que la situación se había dado por zanjada. Posteriormente, tras la sentencia realizada por Majestad Británica, Eduardo VII en 1902, la Patagonia fue dividida, y en el caso de los grandes lagos, estos adquirieron carácter binacional, ya que la línea pasó en medio de ellos, asegurando una mitad para Chile y otra para Argentina, adjudicando a esta última derechos sobre todas aquellas zonas que había comenzado a ocupar, pues significó que "el árbitro se encuentra en presencia de hechos consumados” (Orrego, 1902, p. 182) y por lo tanto, reconoció todas aquellas colonias que ya se habían instalado en la Patagonia, anteriores a los tratados existentes, donde la población se sentía

${ }^{9} \mathrm{El}$ efecto mapa es muy relevante en la formación de las imágenes de un determinado país, pues cualquier ciudadano común generará inconscientemente la idea de que el país vecino es un expansionista, que ha quitado zonas que son legítimas y propias. 
identificada con Argentina. Pero en el caso del territorio de Campos de Hielo Sur, se dejó establecido por separado en uno de los artículos que la zona ya había sido demarcada por mutuo acuerdo de las partes involucradas, como se muestra en este extracto del fallo arbitral de 1902, que tras señalar la división determinaba que:

Artículo III (extracto) La continuación ulterior del límite queda determinada por líneas que hemos fijado cruzando los lagos Buenos Aires, Pueyrredon (o Cochrane) y San Martín, quedando así asignadas las porciones occidentales de las hoyas de estos lagos a Chile, y las Porciones orientales a la Argentina, encontrándose sobre los cordones divisorios los elevados picos llamados monte San Lorenzo y Fitz-Roy. Desde el monte Fitz-Roy hasta el monte Stokes la línea fronteriza ha sido ya determinada (Errazuriz y Carrasco, 1968, p. 108).

La figura 2, es un mapa desarrollado en Chile por la Corporación de Defensa de la Soberanía, muestra la evolución del límite en este punto, desde la línea que señalaba la frontera de 1898, hasta cuando se fueron constituyendo una serie de correcciones, las que hacen alusión a los posteriores acuerdos logrados en el siglo $\mathrm{xx}$, que fueron modificando el límite en esa región.

Sin duda, esta construcción de imagen presente en Internet señala la posición chilena más conservadora del tema en cuestión. Esto nació a raíz de las interpretaciones geográficas del área, donde Chile reconoció el cordón cordillerano oriental como demarcación mientras que para Argentina la sección occidental debía transformarse en la separación, en un ambiente cubierto de hielos que dificultó la investigación en terreno, reflejado en todos aquellos documentos donde se mencionó dicho lugar, generando una dualidad de líneas. Según Rosa (1998), los problemas nacen a mediados del siglo xx:

Las discrepancias en torno a la traza del límite en el sector de los Hielos tomaron forma cuando comenzaron a expresarse a través de los años en la cartografía oficial de ambos países. (...) En el tramo norte concordaron hasta 1953, año en que se publicaron las primeras cartas chilenas apoyadas en fotografías aéreas tomadas por los EEUU en 1947. Dichas cartas se apartaban 
Figura 2. Cambios territoriales mapas de Campos de Hielo

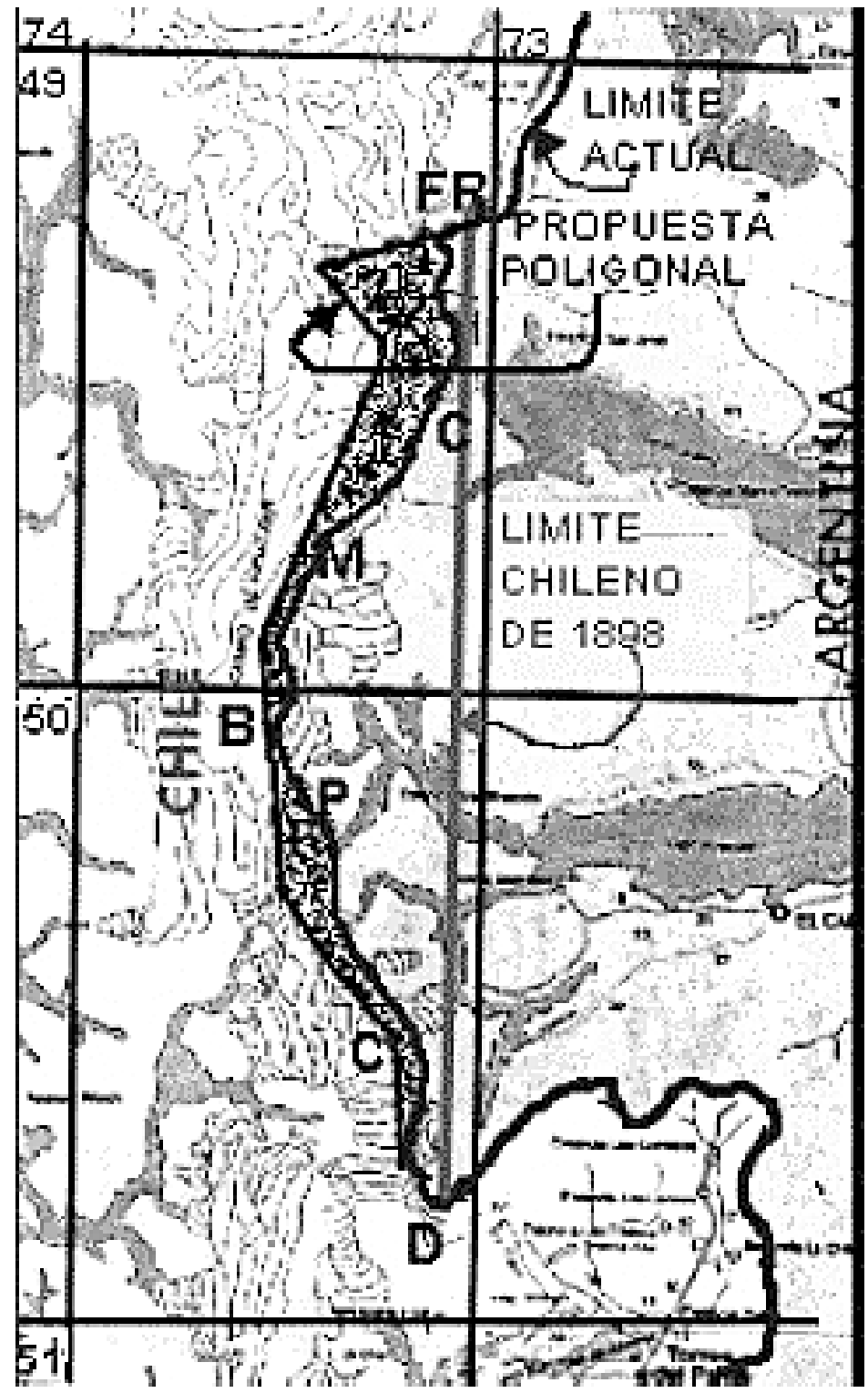

Fuente: Corporación de Defensa de la Soberanía (2010). 
parcialmente del criterio de divisoria continental de aguas. Desde entonces, la discrepancia fue aumentando (Rosa, 1998, p. 140).

Sin duda, esta situación facilitó una representación geopolítica donde Chile se transformó en un "gran competidor" en la zona patagónica, en especial la provincia de Santa Cruz, donde el general Juan Enrique Guglialmelli, describía la situación en la que Argentina se encontraba, luego de analizar la presión demográfica chilena, donde "por último, cabe mencionar, desde la óptica geopolítica, otra especial circunstancia: la perspectiva que toda la provincia se transforme, a corto o mediano plazo, en una frontera con altos niveles de tensión” (Guglialmelli, 1979, p. 261). Sus palabras se relacionan claramente a la crisis del Canal del Beagle, que enfrentaba por esos años a ambas naciones, pero que sin duda, respondían a comprender que la Patagonia, donde se encuentran los Campos de Hielo, se hallaban constantemente presionados por Chile, creándose un imaginario alrededor de esta idea.

Cuando las trazas se volvieron temas inseparables, especialmente por la cantidad de cartografía que representaba al mismo sector en manos diferentes, fue necesario el trabajo de la Comisión Mixta, que al no obtener un acuerdo satisfactorio entre las delegaciones de ambos países, realizaron conversaciones bilaterales a nivel presidencial. El primer intento fue desarrollado en 1991, cuando se estableció la primera poligonal en el sector de Campos de Hielo, mientras que dejaba en manos de un Tribunal Latinoamericano el destino de Laguna del Desierto. Esto generó problemas en ambos países, ya que por parte de Chile, se alegaba que el límite ya estaba claro desde 1898, mientras que en Argentina las dificultades se concentraban en la provincia de Santa Cruz, cuyos habitantes veían que este acuerdo mermaba su territorio. Esta situación muestra que en el interior de Argentina existe una doble representación sobre el problema, la provincial, que ve un riesgo en estos convenios con Chile, y una de carácter central, donde esta línea le permitiría llegar prontamente a un arreglo, favoreciendo ámbitos comerciales como el Mercado Común del Sur (MERCOSUR), considerando que en el sector argentino, la zona se encuentra más poblada que en el lado chileno. Mientras tanto, en Chile, existe una visión muy parecida, ya que aunque algunos sectores y la gente de la región de Aysén rescatan el límite, se mantiene la decisión del gobierno central para 
lograr avanzar en la determinación de una nueva línea, cuyos intentos se consolidaron mediante el Acuerdo de 1998 (DIFrol, 1999), que estableció que la delimitación final se dejaría en manos de una Comisión Mixta de Límites, encargados de dibujar la línea entre el cerro Daudet y Monte Fitz Roy, los últimos puntos en discusión, asegurando las fuentes del río Santa Cruz para Argentina, entendiéndose que:

Para la demarcación en el terreno las Partes encomiendan a la Comisión Mixta de Límites Chile-Argentina, conforme a lo dispuesto en el Protocolo de Reposición y Colocación de Hitos en la Frontera Chileno-Argentina de fecha 16 de abril de 1941 y en el Plan de Trabajos y Disposiciones Generales, la realización de los levantamientos a fin de confeccionar conjuntamente una carta a escala 1:50.000 como requisito imprescindible para llevar a cabo la referida demarcación (DIFROL, 1999, párr. 12).

Analizando la actuación de cada uno de los Estados, se puede comprender que ambos han continuado la elaboración de cartografías. Argentina ha logrado, mediante su ventajosa posición territorial frente a la zona limítrofe, poseer un terreno llano opuesto a lo accidentado del lado chileno, que ha permitido crear una serie de imágenes en la red de servicios turísticos en los alrededores de los Hielos Continentales, relacionadas con el Parque Nacional Los Glaciares, en especial en las zonas cercanas a las ciudades de El Chaltén y Calafate, que resaltan las potencialidades de la zona, pero que no señalan el punto en discusión con Chile. Estos mapas (ver figura 3) se han dado a conocer en diferentes páginas de turismo por Internet, y sin duda, poco ayudan al entendimiento.

Uno de estos mapas turísticos, ampliamente difundido en las redes sociales y en medios internacionales, corresponde a una página dedicada a los glaciares, y que menciona, precisamente, el Parque Nacional Los Glaciares, uno de los circuitos turísticos más importantes de la provincia de Santa Cruz, y donde no se observa el límite que se está desarrollando con Chile. La idea de la manipulación de los mapas, como lo establecía Yves Lacoste, es algo totalmente viable en especial en zonas de baja densidad demográfica y de difícil acceso, como ocurre en este caso, donde en lado argentino no se señala la zona en disputa limítrofe, mientras que en Chile ha ocurrido todo lo contrario, pues en diferentes instancias se rotula que 
Figura 3. Campos de Hielo Sur en mapas argentinos

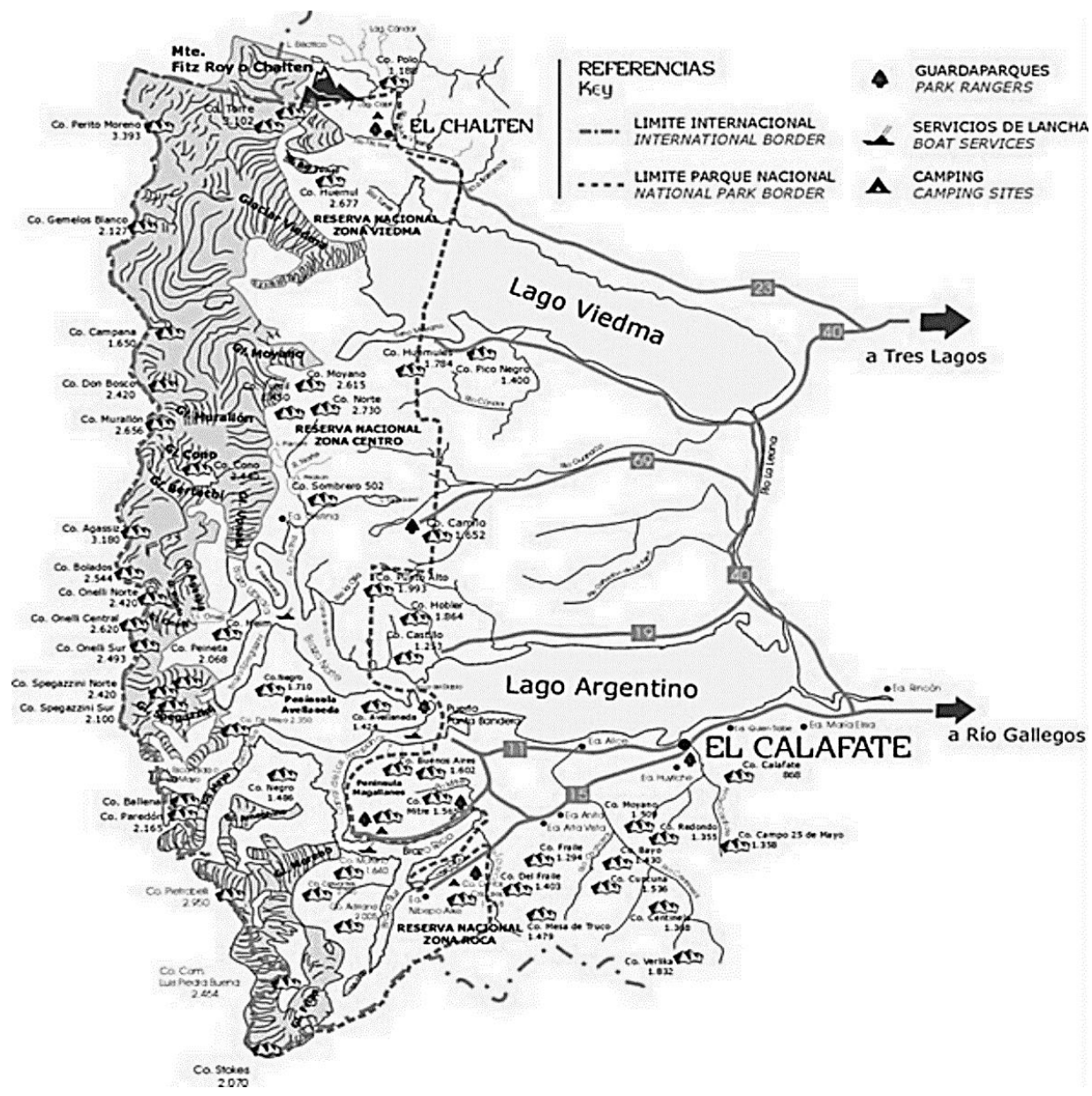

Fuente: Parque Nacional Los Glaciares Argentina (s.f.).

se mantiene el diferendo, mediante una cuadrícula en blanco que menciona el Acuerdo de 1998 (DIFRoL, 1999), especificando que esto seguirá apareciendo mientras no finalice el trabajo de la Comisión Mixta de ambos Estados. Por lo tanto, la presencia o no de esta cuadrícula señalando el problema fronterizo también forma parte del discurso de los Estados, 
generándose una visión internacional frente al tema. La gran existencia de turismo y las imágenes con respecto a la posesión de los glaciares generan una percepción contraria a la resolución del conflicto limítrofe, pues Argentina ha logrado sobre Chile, la creación de una gran cantidad de imágenes en la zona en cuestión.

\section{Cartografía actual}

La situación anterior, demuestra que las divergencias en torno a las imágenes y mapas han continuado a pesar de la existencia de nuevos acuerdos, algo que se logró divisar en el siglo xxi, y con ello, que las prácticas de la representación geopolítica continuaban su accionar en la zona austral. Una de las últimas discrepancias se produjo el año 2010, cuando en la prensa chilena se da a conocer la existencia de un mapa argentino en que se desconocía el Acuerdo de 1998, donde no se explicaban los trabajos de la Comisión Mixta y menos aún, los puntos que se estaban definiendo. Pero esto no constituía el primer incidente con respecto al tema, ya que anteriormente se divulgó que en "el año 2006 a raíz de la publicación de unos mapas por la Secretaría de Turismo de Argentina, que no se ajustaban a lo acordado por ambos países, en cuanto a mostrar la región norte de los Hielos Continentales como pendiente de demarcación, Chile presentó una queja formal al gobierno argentino" (Eissa, 2005, p. 55).

A partir del año 2010, y considerando la situación anteriormente descrita, comenzaron una serie de declaraciones cruzadas que demostraban la molestia del gobierno chileno ante una muestra de que este acuerdo no estaba siendo respetado por su contraparte y más aún, agregaba más kilómetros cuadrados a un problema circunscrito entre el monte Fitz Roy al cerro Daudet. Desde el punto de vista geopolítico, estas imágenes responden al contexto de las representaciones, donde un Estado intenta reflejar ante el mundo su dominio sobre determinadas zonas, en diferentes medios de comunicación (ver figura 4).

Los mapas anteriores, publicados en el diario Clarín, mostraban dos visiones y causaron revuelo dentro de la prensa de ambos países, y por consiguiente con repercusiones en el ámbito político, porque mostraban, por una parte, la imagen de los textos chilenos que demarcaban con una 


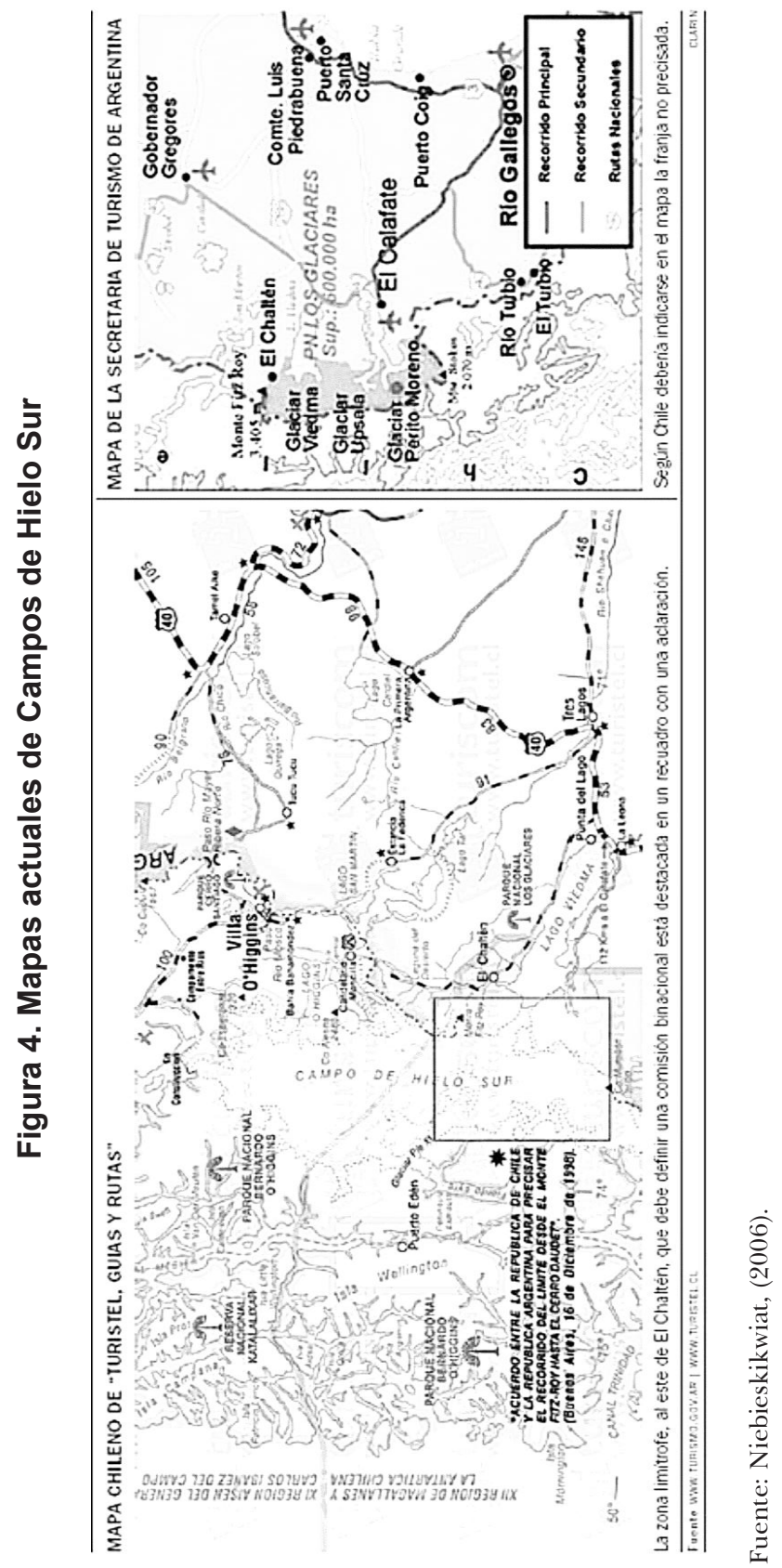


cuadrícula en blanco la zona por demarcar, mientras que en Argentina, empresas de turismo hacían eco de documentos oficiales, para señalar la extensión del Parque Nacional Los Glaciares, y donde no se mencionaba en ningún sentido la línea que se está trabajando. Estas cartografías generaban la idea de que "el establecimiento de una nueva frontera por parte de Argentina que va en contra del acuerdo preestablecido relativo a una zona que se encuentra pendiente, y que Buenos Aires asume como propia en su totalidad" (Faundes, 2008, p. 264), ya que se incluían más zonas de las que se encontraban en el litigio, lo que se produce por los recursos naturales vitales que se ubican en estos glaciares, el agua, clave en el desarrollo de la vida de las personas, tanto en el consumo diario como las actividades económicas que se efectúan con fuerza en el lado oriental, como la agricultura y la ganadería, que sólo cuenta en esa latitud con el río Santa Cruz, el principal cauce de la región, pero además con una población en continuo crecimiento en sus ciudades que en un futuro cercano, demandarán más cantidad de agua para sus necesidades básicas.

Lo anterior causó tensión en las buenas relaciones vecinales que se habían desarrollado desde el Tratado de 1984, motivando la creación de las Medidas de Confianza Mutua en áreas políticas, militares y científicas, las cuales, sólo un año antes de la aparición de esta cartografía, se habían ratificado a través de la firma del Tratado de Maipú, entre los gobiernos de Michelle Bachelet y Cristina Fernández. Además, se han seguido desarrollando visiones contrapuestas defendidas por los parlamentarios de las zonas en cuestión, como el Senador Antonio Horvath (Chile) que estima, con respecto a Campos de Hielo Sur:

En el lado chileno eso corresponde al Parque Nacional O'Higgins y en el argentino al Parque Los Glaciares, sin embargo, los argentinos le sacan un provecho turístico y de marca de nivel internacional, de hecho ellos en sus mapas ponen el área en litigio como propia. Una vez más, Chile no se tiene que apegar a lo legal y debe hacer una presencia pacífica en el sector con mapas, documentos, estudios, ciencia, recreación, turismo y si bien tenemos más dificultad de acceder, tenemos el mismo derecho de sacarle provecho (Francino, 2014, párr. 8). 
Por lo tanto, mientras las representaciones geopolíticas sigan presentes en las acciones de los Estados, que se han rodeado de imágenes para crear una visión o imaginario dentro de la población, especialmente cuando las zonas en discusión se encuentran lejanas de los centros administrativos más relevantes de cada uno de ellos. En este caso, Campos de Hielo Sur cumple con estos requisitos, ya que algunos años atrás, este lugar se encontraba alejado y desconocido para la gente, pero los mapas permitían afirmar este sentimiento de unidad con estos lugares, mientras que los habitantes más cercanos, en su mayoría en el lado argentino, también desarrollan la pertenencia con esta área y la rivalidad con la visión estatal que puede pensar en el bien nacional por sobre el regional. Mientras las representaciones se mantengan presentes, los problemas fronterizos continuarán presentes, y con ello, dificultarán los procesos de integración que se han fijado, ya que la cartografía demuestra que todavía, a pesar de los avances, se mantienen dentro de su mentalidad la idea de competencia y de obtención de territorio por sobre el otro.

\section{Consideraciones finales}

La geopolítica, cuyo origen se encuentra en la geografía, nos entrega importantes visiones sobre el comportamiento de los Estados, los cuales, a lo largo de su historia se han movilizado de acuerdo a sus intereses, en diferentes lugares a su alrededor. En medio de ello, la idea de representación, que es finalmente la imagen a proyectar en un territorio, a través de los mapas, fue y será clave en la relación chileno-argentina con respecto a la Patagonia, extensa pampa que por su latitud constituye una zona de baja densidad demográfica y rica en recursos naturales, donde los mapas han proyectado un imaginario que permite identificarse con los lugares que se encuentren en disputa. Sin duda, el mapa constituye una herramienta poco inocente, pues con ello se puede observar cómo se ve el Estado en cuestión frente al mundo, como también las zonas que pretende objetar u ocupar en el futuro frente a sus vecinos o rivales más cercanos. Desde las primeras reclamaciones territoriales, los mapas creados bajo las autoridades españolas fueron utilizados para adjudicar o demostrar las actitudes poco amistosas del país vecino, creándose una representación donde el 
otro es un expansionista y donde las dudas sólo aseguraron dificultades en el futuro.

Campos de Hielo Sur es uno de los puntos que cumple con este requisito, ya que siendo un lugar mayoritariamente deshabitado en el lado chileno y con mayor densidad en el lado argentino, demuestra que se ha construido una representación geopolítica con el paso de los años, donde su lejanía ha necesitado crear un imaginario a su alrededor para que la gente se identifique con los reclamos territoriales de los Estados. Esto se puede observar en la gran cantidad de mapas contrapuestos en sitios públicos de la web, donde la gente logra llegar fácilmente a la información, y crear una visión a partir de lo que miran en estas páginas, ya que en su mayoría, no tienen acceso a los documentos y cartografías oficiales de cada uno de ellos. Si estos mapas generan una visión a nivel nacional y regional, también ocupan un rol internacional relevante, por lo que la labor que ejercen las imágenes es muy influyente, pues ayuda en la creación de una percepción errada de la realidad si estos omiten los trabajos de las comisiones limítrofes en el área. Desde el establecimiento del primer límite conocido, en el año 1898, la línea ha sido modificada en varias ocasiones, hasta llegar al último acuerdo, que en 1998 dejaba en manos de una Comisión Mixta la demarcación final en este punto, señalando que hasta que los trabajos terminaran, se debía expresar en todos los mapas oficiales esta situación.

Los últimos malos entendidos, surgidos tras la publicación de la cartografía en Argentina en 2010, donde se desconocía el Tratado de 1998 y la línea poligonal entre los cerros Daudet y Fitz Roy, adjudicándolos a este país por completo, demostró que la presencia de mapas con esas características son más comunes de lo que se pensaba, ya que en páginas dedicadas al turismo, se entregaba una mayor cantidad de kilómetros de Campos de Hielo Sur o Hielos Continentales a Argentina que Chile, mientras que este último explicaba mediante una cuadrícula en blanco la presencia de un acuerdo pendiente en la Comisión Mixta de Límites binacional. Estos problemas llevarían a una discusión bilateral sobre el límite, pero además generó una visión de desconfianza, en que Argentina está utilizando las representaciones geopolíticas para discutir la división de los Campos de Hielo o los Hielos Continentales. Con ello, nuevamente se impone la percepción de expansionismo por parte de uno de 
los Estados involucrados, ya que no señala los trabajos demarcatorios y el acuerdo firmado en 1998.

Sin duda, estas representaciones e imágenes son claves, pues el mantenimiento de estas cartografías sobre determinadas áreas de un territorio sólo demuestran que para los Estados involucrados, existen intereses en particular, por lo cual, les importa señalar frente al mundo cuáles son sus intenciones, generándose a través de la herramienta de los mapas una importante señal, que se traduce en una percepción propia de la ciudadanía chilena y argentina, donde las desconfianzas se imponen por sobre los esfuerzos de integración que vienen desarrollando desde la firma del Tratado de paz y amistad de 1984 (DIFROL, 1985), donde se acordaron medidas de confianza mutua para avanzar en una agenda común que solucionase los acuerdos por medios diplomáticos. Sin duda, las riquezas que tiene este territorio, en especial, las reservas de agua que posee, son claves en el desarrollo de los Estados en el futuro, por lo tanto, la presencia de tales imágenes sólo responde a la idea de representación geopolítica, donde los Estados involucrados esperan que se perciban sus intereses en el plano internacional y cuáles son sus reales proyecciones a futuro en estos casos. Sin duda, aunque se encuentre presente el acuerdo de 1998 en Campos de Hielo Sur, esta zona no ha terminado su demarcación aún, ya que a pesar de que existen puntos en la poligonal, las labores dentro de la Comisión Mixta de Límites no ha finalizado, por lo que se continuarán creando una serie de mapas que entreguen una representación geopolítica desde Chile o Argentina, donde alguno de los involucrados se sienta perjudicado frente al otro.

\section{Referencias}

Agnew, J. (2005). Geopolitica una re-visión de la Política Mundial. Madrid, España: Trama.

Agostini, A. (1945). Andes Patagónicos. Buenos Aires, Argentina.

Aguer, B. (2014). Geopolíticas del conocimiento tras la proyección Mercator. Avatares Filosóficos, (1), 130-141.

Amunátegui, M. (1880). La cuestión de límites entre Chile y Argentina. Santiago, Chile: Imprenta Nacional.

Barros, M. (1970). Historia diplomática de Chile 1541-1938. Santiago, Chile: Andrés Bello. 
Berdoulay, V. (2012). El sujeto, el lugar y la mediación del imaginario. En A. Lindón y D. Hiernaux (Dir.), Geografías de lo imaginario (pp. 49-65). Madrid, España: Antropos.

Börgel, R. (1995). Delimitación en el Campo de Hielo Sur. Revista de Geografía Norte Grande, (22), 9-14.

Claval, P. (2012). Mitos e imaginarios en geografía. En A. Lindón y D. Hiernaux (Dir.), Geografías de lo imaginario (pp. 29-48). Madrid, España: Antropos.

Congreso Nacional. (2009). Informe de la Comisión Especial de Campo de Hielo Patagónico Sur. Valparaíso, Chile: Comisión Especial de Campo de Hielo Patagónico Sur.

Corporación de Defensa de la Soberanía. (2010). Campo de Hielo Sur. Recuperado de www.soberaniachile.cl

Dirección Nacional de Fronteras y Límites del Estado (DIFROL). (1881). Tratado de Limites de 1881. Recuperado del sitio de Internet de DIFrol Ministerio de Relaciones Exteriores, Gobierno de Chile: http://www.difrol.gob.cl/argentina/ tratado-de-limites-de-1881.html

Dirección Nacional de Fronteras y Límites del Estado (DIFroL). (1985). Tratado de Paz y Amistad de 1984. Recuperado de http://www.difrol.gob.cl/argentina/ tratado-de-paz-y-amistad-de-1984.html

Dirección Nacional de Fronteras y Límites del Estado (DIFROL). (1999). Acuerdo para precisar el recorrido del límite desde Monte Fitz Roy hasta el Cerro Daudet. Recuperado del sitio de Internet de Difrol Ministerio de Relaciones Exteriores, Gobierno de Chile: http://www.difrol.gob.cl/argentina/acuerdo-para-precisarel-recorrido-del-limite-desde-el-monte-fitz-roy-hasta-el-cerro-daudet.html

Eissa, S. (2005). Hielos Continentales. La politica exterior argentina en los 90'. Buenos Aires, Argentina: Centro Argentino de Estudios Internacionales.

Errazuriz, O. y Carrasco, G. (1968). Las relaciones chileno argentinas durante la Presidencia de Riesco (1901-1906). Santiago, Chile: Andrés Bello.

Faundes, C. (2008). El agua como factor estratégico en la relación de Chile y los países vecinos. Santiago, Chile: Academia Nacional de Estudios Políticos y Estratégicos.

Francino, R. (31 de enero de 2014). Horvath advierte sobre pasividad chilena en Campos de Hielo. Recuperado de http://noticias.terra.cl/chile/horvath-adviertesobre-pasividad-chilena-en-campos-de hielo,55fa82c4e35e3410VgnVCM300 0009af154d0RCRD.html

Goudin, P. (2010). Diccionario de Geopolítica. París, Francia: Choiseul.

Guglialmelli, J. E. (1979). Geopolítica del Cono Sur. Buenos Aires, Argentina: El Cid. Herrero, R. (2006). La realidad inventada. Percepciones y proceso de toma de decisiones en Política Exterior. Madrid, España: Plaza y Valdés.

Instituto de los Andes. (s.f.). Virrenato del Perú (01-10). Recuperado de http:// gerencia.blogia.com/2015/031601-el-virreinato-del-peru-01-10-.php 
Lacoste, P. (2002). La guerra de los mapas entre Argentina y Chile. Una mirada desde Chile. Historia, (35), 211-249.

Lacoste, P. (2004). La imagen del otro en las relaciones de la Argentina y Chile (15342000). Santiago, Chile: Fondo de Cultura Económica.

Lacoste, Y. (1990). La geografía, un arma para la guerra. Barcelona, España: Anagrama.

Laurín, A. y Núñez, A. (2013). Frontera, globalización y deconstrucción estatal. Hacia una geografía política crítica. En M. A. Nicoletti y P. Núñez (Comps.), Araucania- Norpatagonia: la territorialidad en debate (pp. 83-100). Bariloche, Argentina: Instituto de Investigaciones en Diversidad Cultural y Procesos de Cambio.

Los Glaciares. (s.f.). Parque Nacional Los Glaciares Argentina. Aspectos generales. Recuperado de www.losglaciares.com/es/parque

Lucero, M. (2007). El poder legislativo en la definición de la Política Exterior Argentina. El caso de los Hielos Continentales Patagónicos. Cuadernos de Política Exterior Argentina, 90, 1-124.

Niebieskikwiat, N. (29 de agosto de 2006). Hielos continentales, reclamo de Chile por mapas argentinos. Diario Clarín. Recuperado de http://edant.clarin.com/ diario/2006/08/29/elpais/p-01201.htm

Nogué, J. (2012). Intervención en imaginarios paisajísticos y creación de identidades territoriales. En A. Lindón y D. Hiernaux (Dirs.), Geografías de lo imaginario (pp. 129-139). Madrid, España: Antropos.

Orrego, L. (1902). Los problemas internacionales de Chile. La cuestión argentina, el Tratado de 1881 y negociaciones posteriores. Santiago, Chile: Esmeralda.

Rosa, C. L. de la (1998). Acuerdo sobre los Hielos Continentales: razones para su aprobación. Mendoza, Argentina: Ediciones Jurídicas Cuyo.

Tratado de paz, amistad, comercio y navegación de 1856. Artículo 39.

Zamora, J. (s.f.). Historia de las fronteras de Chile. Recuperado de http://mediateca. $\mathrm{cl} / 900 /$ historia/chile/fronteras/fronteras\%20de $\% 20$ chile $\% 20$ independencia. $\mathrm{htm}$ 